Thorax, 1980, 35, 513-514

\title{
Effect of a change to mite-free bedding on children with mite-sensitive asthma: a controlled trial
}

\author{
M L BURR, E NEALE, B V DEAN, AND E R VERRIER-JONES \\ From the MRC Epidemiology Unit, Cardiff, Sully Hospital and Llandough Hospital, \\ South Glamorgan
}

\begin{abstract}
AISSTRACT Twenty-one children with mite-sensitive asthma took part in a crossover randomised controlled trial of mite-free bedding. Each child was issued with a new sleeping bag and pillow for a month, and twice-daily peak flow readings were compared with those obtained during a month in the child's ordinary bedding. Seventeen of the children had higher mean peak flow readings during the period in the mite-free bedding $(\mathrm{p}<0.01)$. The overall improvement was only modest, however, and some mites had appeared in most of the bedding by the end of the trial. New bedding may be helpful to patients with mite-sensitive asthma, but methods are needed to prevent colonisation by mites.
\end{abstract}

In a randomised controlled trial among children with mite-sensitive asthma rigorous anti-mite measures did not seem to confer any greater benefit than a placebo procedure. ${ }^{1}$ This may have been the result, in part at least, of the failure of these measures to eradicate mites from the children's bedding. A further trial was, therefore, conducted to examine the effect of a change to mite-free bedding.

\section{Subjects and methods}

The subjects were all children with mite-sensitive asthma who had taken part in the previous trial. Those who still complained of frequent symptoms and who seemed to be suitable on other grounds were asked to participate in a further study. This trial involved a complete renewal of bedding, and a crossover design was used. Each child was randomly allocated to a treated or a control group for one month, and the two groups were then transposed for a further month.

During the "treatment" period each child was provided with a newly purchased sleeping bag and a new pillow, new blankets also being supplied if required. The child's mattress was completely enclosed in an impervious plastic bag. All other bedding in the child's bedroom was either enclosed in impervious bags or removed and replaced (if in use) by new sleeping bags and pillows. The carpets in the bedrooms were

Address for reprint requests: Dr ML Burr, MRC Epidemiology Unit, 4 Richmond Road, Cardiff CF2 3AS. vacuum cleaned several times every week. The children were issued with peak flow gauges and they recorded three readings each morning and evening, the highest reading on each occasion being used in subsequent calculations. During the control period no special placebo procedure was adopted except in so far as the measures advocated in the previous trial were still being practised. Some of the sleeping bags, pillows, and blankets were sampled for mite counting when they were first issued and again (after being laundered) before being issued to the second treated group. At the end of the trial each mother was asked whether the child had been better or worse during the period in the sleeping bag.

\section{Results}

Because of the lapse of time since the first trial (up to two years) the original 53 children were not all available for this study. Several no longer regularly suffered from symptoms, some had moved away, some refused to co-operate further, and some were excluded because of enuresis or other factors in their sleeping arrangements making them unsuitable for this trial. Twentyone children remained who still had active asthma and whose mothers were willing and able to participate. For 10 of these children the "treatment" period preceded the control period while in 11 the control period was first.

Table 1 contains a summary of the peak 
Table 1 Peak flow readings during control and treated periods

\begin{tabular}{|c|c|c|c|c|c|}
\hline & \multicolumn{2}{|l|}{ Control period } & \multicolumn{2}{|l|}{ Treated period } & \multirow{2}{*}{$\begin{array}{l}\frac{\text { Treated PFR }}{\text { Control PFR }} \% \\
\text { (geometric mean) }\end{array}$} \\
\hline & $\begin{array}{l}\text { Mean number } \\
\text { of readings }\end{array}$ & $\begin{array}{l}\text { Coefficient of } \\
\text { variation } \\
\text { mean } \pm S E\end{array}$ & $\begin{array}{l}\text { Mean number } \\
\text { of readings }\end{array}$ & $\begin{array}{l}\text { Coefficient of } \\
\text { variation } \\
\text { mean } \pm S E\end{array}$ & \\
\hline $\begin{array}{l}\text { Morning peak flow readings } \\
\text { Evening peak flow readings }\end{array}$ & $\begin{array}{l}27 \cdot 3 \\
27 \cdot 7\end{array}$ & $\begin{array}{l}14 \cdot 6 \pm 1 \cdot 6 \\
12 \cdot 9 \pm 1 \cdot 3\end{array}$ & $\begin{array}{l}26 \cdot 3 \\
26 \cdot 4\end{array}$ & $\begin{array}{l}11 \cdot 6 \pm 1 \cdot 4 \\
12 \cdot 2 \pm 1 \cdot 4\end{array}$ & $\begin{array}{l}105 \cdot 8 \\
103 \cdot 2\end{array}$ \\
\hline
\end{tabular}

flow readings in the two groups. For each child the coefficient of variation of morning and evening readings was calculated as an index of airflow variability. The variability of morning peak flow readings was less during the treated period than during the control period, but the difference did not achieve statistical significance (using Wilcoxon's matched-pairs signed-rank test). The mean peak flow reading for each child during the treated period was expressed as a percentage of the corresponding mean value for the control period. The geometric means of these percentages are greater than 100 for both morning and evening readings (especially the former), but not significantly so.

In table 2 the children are classified according to whether their mean peak flow readings were higher during the treated or the control periods. The majority of the children had higher mean values during the treated period, and a sign test shows this to be statistically significant $(\mathrm{p}<0.01)$.

The mothers were asked whether they thought their children's asthma was better or worse during the period in the sleeping bag. Six thought their children had improved, one was worse, while 14 had not shown any change obvious to their parents.

Mite counting showed that the bedding was entirely free from mites when it was first issued. After being used for a month and laundered the sleeping bags and blankets contained one or two

Table 2 Numbers of patients better during treated or control periods

\begin{tabular}{lll}
\hline & $\begin{array}{l}\text { Morning } \\
\text { readings }\end{array}$ & $\begin{array}{l}\text { Evening } \\
\text { readings }\end{array}$ \\
\hline Treated PFR > Control PFR & 17 & 17 \\
Control PFR > Treated PFR & 4 & 4 \\
All subjects & 21 & 21 \\
\hline
\end{tabular}

mites per sample or none at all, but after the $\vec{\omega}$ second period of use some contained up to 10 mites per $10 \mathrm{~cm}$ square.

\section{Discussion}

This trial was undertaken because of the dis- $\omega$ appointing results of the trial of mite eradication. The children all had mite-sensitive asthma, $\vec{c}$ and it was hoped that a period in mite-free bedding would provide a further test of the importance of mites in provoking asthma in $\operatorname{such}_{\infty}^{\infty}$ patients.

The results were in no way dramatic; the overall improvement was only modest, and in terms of a change in coefficient of variation or mean⿳亠二口 improvement in peak flow reading it did not气 achieve statistical significance. But the majority $\mathbb{Q}$ of subjects ( 17 out of 21 ) were better in the mite- $\overrightarrow{\vec{O}}$ free bedding than during the control period with 3 respect to both morning and evening readings, $\supset$ and this is unlikely to have occurred by chance $(p<0.01)$. These findings support the observations of Wraith and Cunnington ${ }^{2}$ who recom-o mended the removal of old articles of bedding which from extensive reservoirs of mite infesta-o tion and are largely unaffected by hygiene control measures. Even within the duration of the trial the bedding began to be colonised by $₹$ mites, so it is clear that further thought musto be given to devise means of keeping new bedding free from mites.

\section{References}

1 Burr ML, Dean BV, Merrett TG, Neale E,N Verrier-Jones ER. Effects of anti-mite measures ${ }^{\omega}$ on children with mite-sensitive asthma: a controlled trial. Thorax 1980; 35:506-12.

2 Wraith DG, Cunnington AM. The mite and childhood asthma. Br Med J 1975; 3:766. 